\title{
SOFC characteristics along the flow path
}

\author{
P. Metzger*, K.-A. Friedrich, H. Müller-Steinhagen, G. Schiller \\ German Aerospace Center (DLR), Institute of Technical Thermodynamics, D-70569, Stuttgart, Germany
}

Received 1 July 2005; received in revised form 19 June 2006; accepted 20 June 2006

\begin{abstract}
Solid oxide fuel cells (SOFCs) in metallic housings were integrally and locally characterised. The tests were performed in counter flow operation for hydrogen concentrations from $2 \%$ to $100 \%$, to identify concentration limitations and to optimise fuel utilisation. Cell characterisations were performed by spatially resolved electrochemical impedance spectroscopy (EIS), current density/voltage ( $i-V)$ and temperature measurements as well as gas chromatography measurements at 16 distinct points across the cell. The results show a substantial variation of current density and voltage distribution along the flow path with varying hydrogen content and fuel utilisation. The fuel utilisation was calculated from the local current densities and compared to the values measured by gas chromatography. Both sets of results showed good agreement. At low hydrogen inlet concentrations the voltage at the fuel outlet drops to values that might be harmful for the stability of the anode since reoxidation of nickel can occur. The impedances obtained by local EIS did not show an overall coherent dependency on the hydrogen concentration. EIS under load revealed two distinct domains: in the range of hydrogen concentrations of $2-10 \% \mathrm{H}_{2}$ the impedance decreased significantly with increasing hydrogen content whereas at higher hydrogen contents the impedance was hardly affected. This indicates significant concentration and diffusion overpotential at low hydrogen concentrations. The local data showed differing behaviour in the middle of the cell compared to the fuel outlet. Leakage at the sealing could be identified as a possible reason. As an additional method of investigation, the voltage drop over the contact resistance of the cathode side was measured. Temperature measurements show that local temperatures differ significantly depending on the load applied to the cell. This observation emphasizes the importance of a thermal management adapted to the characteristics on operation conditions of the cells, particularly when the stack itself has only a low mass.
\end{abstract}

(C) 2006 Elsevier B.V. All rights reserved.

Keywords: SOFC; Contact resistance; Local characteristics; Impedance spectroscopy

\section{Introduction}

Progress in the development of SOFC resulted in high power densities and the ability to use hydrocarbons as a fuel [1]. For technical applications the cells are integrated in a metallic housing and the gas supply is accomplished through channels. The high power densities of laboratory cells decrease significantly when the cell size is extended to technically relevant dimensions and the fuel utilisation is adjusted to acceptable levels. The performance losses are, for example, attributed to local mass transports effects, unevenly manufactured layers and, as a result, differing contact resistance over the cell area $[2,3]$. Due to the electrochemical

\footnotetext{
* Corresponding author.

E-mail addresses: patrick.metzger@dlr.de (P. Metzger), andreas.friedrich@dlr.de (K.-A. Friedrich), guenter.schiller@dlr.de (G. Schiller).
}

reaction, gradients of the reactant and product composition can be observed along the flow path of the gases. Especially high fuel utilisations lead to a depletion of the fuel along the flow path and to varying power densities. Furthermore, the electrochemical reaction is associated with heat production, resulting in temperature gradients in such a system.

To optimise cells for operation in highly efficient systems a new measurement system is needed that allows the determination of local effects and the identification of critical parameters for operation [4]. The spatial resolution that is incorporated in the developed system allows the identification of possible steep gradients along the flow path.

\section{Experimental}

Square-shaped cells with a size of $100 \mathrm{~cm}^{2}$ were integrated in metallic housings and sealed with glass sealing provided by the 
Fraunhofer Institute for Ceramic Technologies and Sintered Materials (IKTS) in Dresden. The metallic housing is subdivided into 16 galvanically isolated segments on both sides resulting in an active area of $73.96 \mathrm{~cm}^{2}$. The electrical circuit of the current is shown in Fig. 1. Since the resistances in the current wires lead to a non-ideal electrical connection of the segments, an equipotential line could only be found in the current bus bar whereas the potential of the segments can differ tremendously. As an effect depending on the test conditions the internal resistances can play a minor role in comparison to the resistances of the wires and therefore lead to misinterpretations of the results. Taking the nonideal electrical connection of the segments into account the obtained results reflect the local conditions reliably. During the measurement of the $i-V$ curves the current and the voltage are controlled by a common electronic load. In Fig. 2(a) the schematic layout of the metallic housing is illustrated, showing an electrolyte supported cell (ESC2) which consists of a subdivided anode and cathode. In Fig. 2(b) an anode supported cell (ASC2) that for stability reasons is only sectioned on the cathode side is shown. The ESC2 cell (InDEC, Netherlands) cell consists of a $45 \mu \mathrm{m}$ thick nickel oxide/gadolinia doped ceria $(\mathrm{NiO} / \mathrm{GDC})$ anode, a $90 \mu \mathrm{m}$ thick yttria stabilised zirconia (3 mol\%) (TZ3Y) electrolyte and a $40 \mu \mathrm{m}$ thick LSM cathode. The ASC 2 cell (InDEC) consists of a standard $540 \mu \mathrm{m}$ thick $\mathrm{NiO} /$ YSZ anode with thin anode functional layer, a $7 \mu \mathrm{m}$ thick yttria stabilised zirconia (8YSZ) electrolyte and a $7 \mu \mathrm{m}$ thick yttria doped ceria (YDC) layer to prevent chemical interaction with the adjacent $30 \mu \mathrm{m}$ thick lanthanum strontium cobaltite ferrite (LSCF) cathode. For the contact of the electrodes, nickel and platinum meshes were inserted. The measuring system allows the determination of the current density/voltage $(i-V)$ characteristics, impedance and temperature data over the complete cell and at the

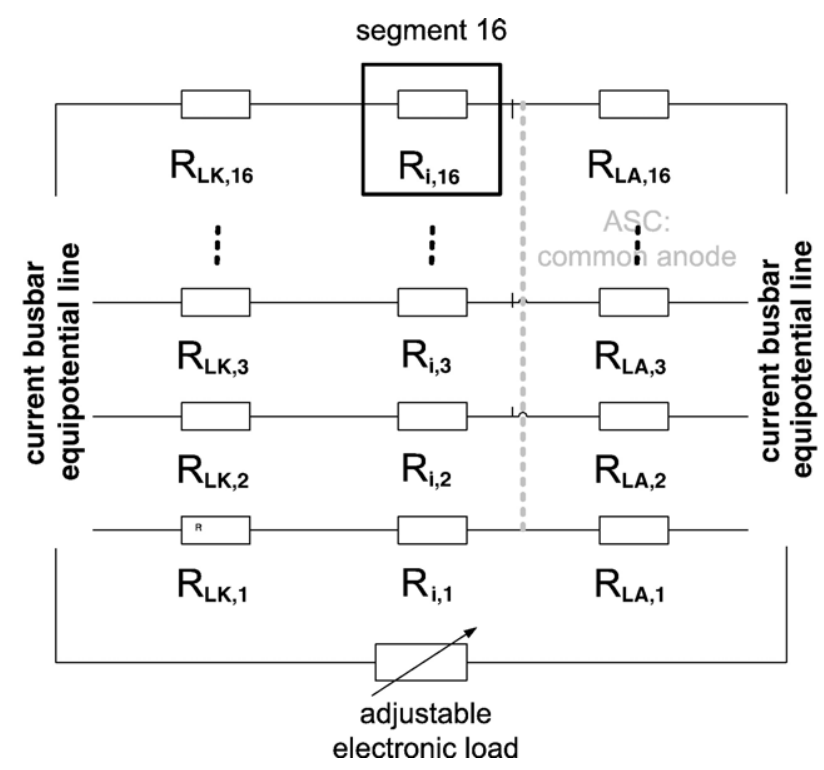

Fig. 1. Schematic layout of the electrical circuit of the segmented cell configuration. The internal cell resistances are abbreviated with $R_{i, j}$, the resistances of the wires contacting the anode with $R_{\mathrm{LA}, j}$ and the resistances of the wires contacting the cathode with $R_{\mathrm{LK}, j}$. For clarity only the measurement of the $i-V$ curves is considered and only the segments 1, 2, 3, 16 are illustrated.
16 distinct segments. Additionally, auxiliary voltage probes were integrated in the middle of 4 of the 16 segments along the flow path at the cathode side. These voltage probes were isolated from the metallic segments and are in direct contact with the cathode surface, allowing measurement of the over-voltages related to the cathodic contact resistance [5]. A schematic diagram of the integration of the voltage probes is shown in Fig. 3. To determine the balance of the anode gases, capillary tubes were integrated in the middle of the segments at the anode side. The sample gas composition was determined by gas chromatography. For details of the measuring system the reader should refer to [2].

\section{Results and discussion}

\subsection{Variation of the hydrogen content}

The content of hydrogen in the fuel gas supplied to an ESC2 cell was varied between $2 \%$ and $100 \%$ (the supplementary gas was $\mathrm{N}_{2}$ ). The power density distribution remains homogeneous when the system is operated at low fuel utilisations $\left(f_{\mathrm{u}}<25 \%\right)$, as can be seen in Fig. 4(a). With higher fuel utilisations significant gradients in the power density could be observed, resulting from both the variation of current density and voltage along the flow channels. At a hydrogen level of $10 \%$ the fuel utilisation already reaches nearly $80 \%$ at the fuel outlet. Although the fuel utilisation is already high the differences in the power densities from 149.5 to $184.3 \mathrm{~mW} / \mathrm{cm}^{2}$ vary only by about $20 \%$. With even lower hydrogen content the fuel utilisation which is calculated from the average current density of the segments in the considered segment line reaches levels of nearly $100 \%$ or even above $100 \%$. Utilisations above $100 \%$ are not real but the result of the assumption that the gas distribution between the $4 \times 4$ matrix of the 16 segments (see arrangement of the segments in Fig. 5) is homogeneous and that every segment line is fed with the same amount of gas, resulting in an identical residence time. In reality the current density distributions imply that the middle segment lines are supplied with a higher amount of gas. Nevertheless, the assumption is maintained for the rest of the calculations because the distribution between the four segment lines could not be determined experimentally. The occurring systematic error affects all concentration values and therefore does not influence trends and the comparison of results. At $2 \%$ hydrogen content, segment 8 at the fuel exit contributes very little to the overall power density and only reaches a value of $8.8 \mathrm{~mW} / \mathrm{cm}^{2}$ compared to $87.1 \mathrm{~mW} /$ $\mathrm{cm}^{2}$ at segment 5 . The differences in the power density at higher hydrogen contents $(20 \%$ or more) are about $10 \%$ or less and therefore hardly noticeable. To verify the calculated levels of the fuel utilisation they are compared with the values measured with the gas chromatograph at $2 \%, 10 \%$ and $50 \%$ hydrogen content in Fig. 4(b). The graph shows good agreement between the measured and the calculated values. The measured values are slightly higher which is due to the geometrical conditions in the cell. While the gas sample is analysed from the gas channel, the calculated 


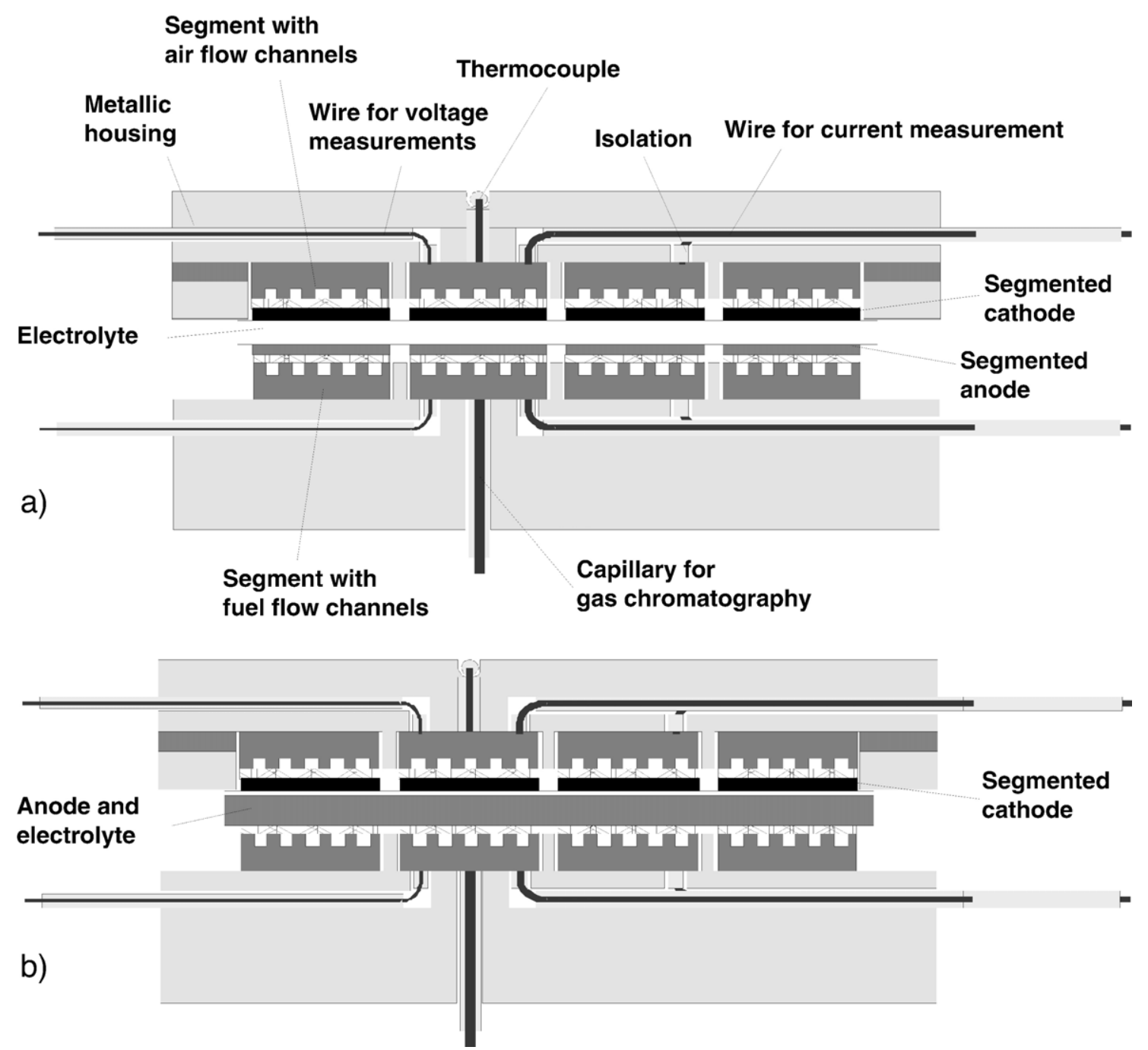

Fig. 2. The segmented cell approach of DLR for SOFC; schematic representation of the metallic housing which is segmented on both sides; (a) housing with electrolyte supported cell, (b) housing with anode supported cell.

values represent the concentration levels at the triple phase boundary of the anode. The gas velocity in the flow channels is about $1.4 \mathrm{~m} / \mathrm{s}$. Hence an equivalence of concentration levels in the gas channel and at the triple

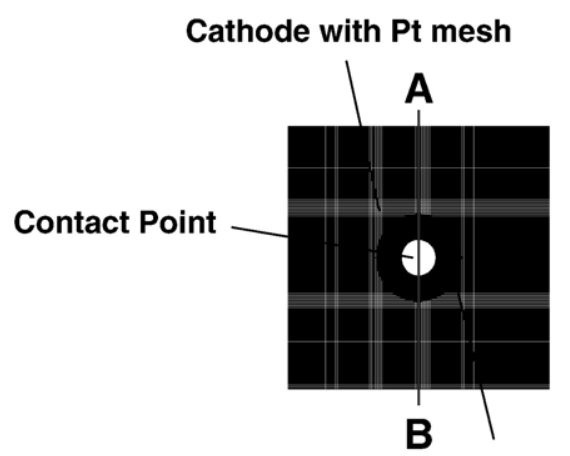

Removed Pt mesh phase boundary is not reached, due to effects of surface gradients and gas boundary layer. The relative values vary, according to the above-mentioned consideration, more at lower hydrogen levels than at higher ones.

Wire for additional

Voltage measurements

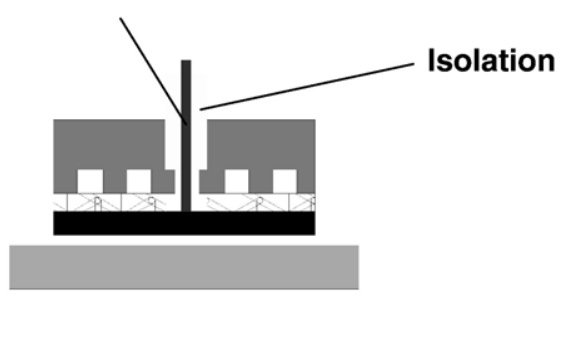

Fig. 3. Schematic representation of contact resistance measurement in the segmented cell design. Top view and cross view of a metallic segment with an additional contact wire contacting an anode supported cell. 

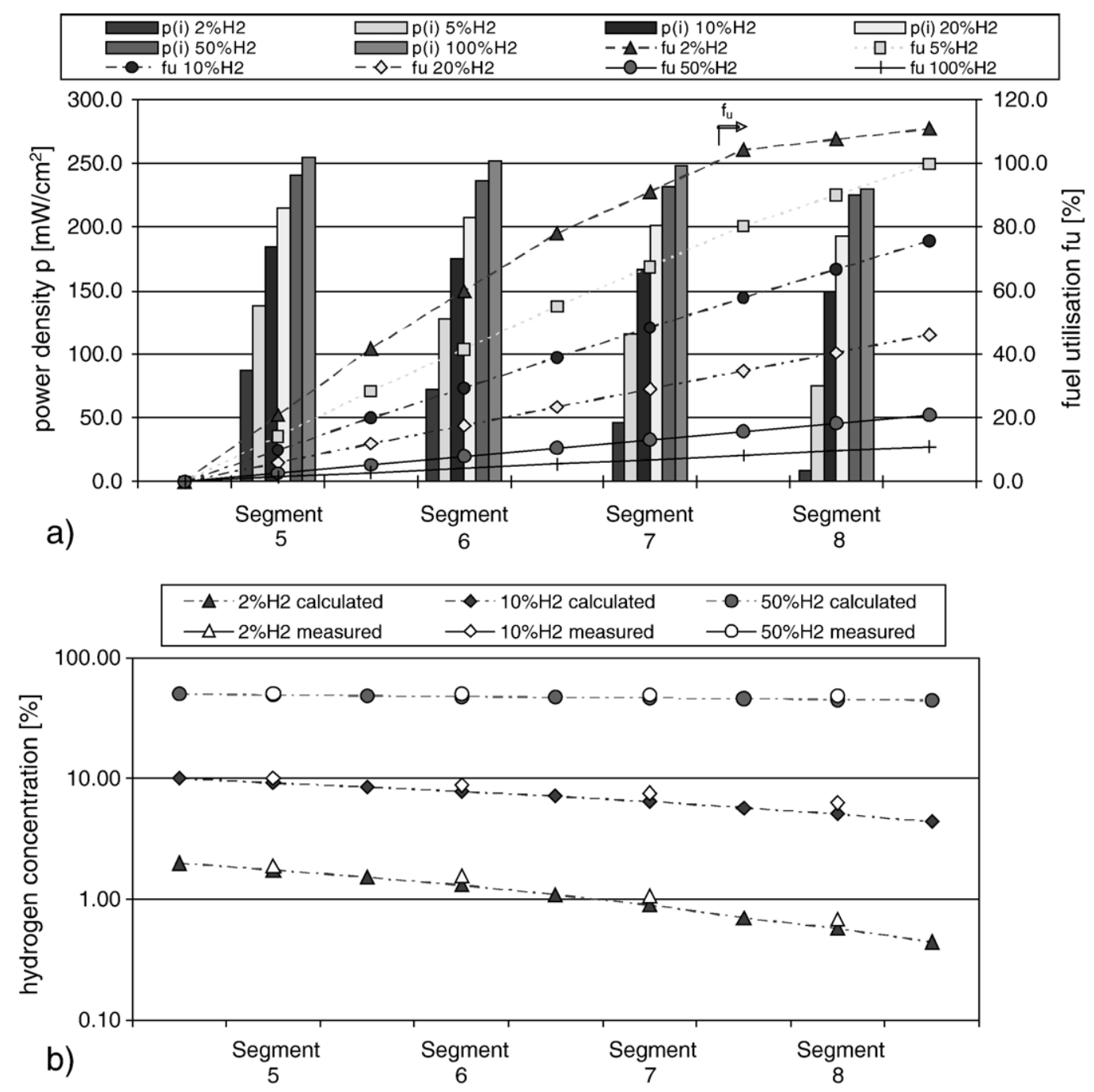

Fig. 4. (a) Locally resolved power density distribution (filled bars) and fuel utilisation (filled symbols) for different hydrogen concentrations of the electrolyte supported cell ESC2 (INDEC). (b) Comparison of calculated (filled symbols) and measured hydrogen concentration (open symbols) by gas chromatography for a segment row in the ESC2 cell. Average cell voltage: $0.6 \mathrm{~V}$, operating temperature: $800{ }^{\circ} \mathrm{C}$, fuel flow: 0.025 standard liters per minute $(\mathrm{SlpM}) / \mathrm{cm}^{2} \mathrm{H}_{2}+\mathrm{N}_{2}+3 \% \mathrm{H}_{2} \mathrm{O}$, oxide gas flow: $0.08 \mathrm{SlpM} / \mathrm{cm}^{2}$ air, $73.96 \mathrm{~cm}^{2}$, fuel is entering from the left side at segment 5 .

The effect of varying gas concentration and electrochemical reaction along the flow path on the voltage distribution is shown in Fig. 5. Particularly Fig. 5(a) and (f) at hydrogen levels of $2 \%$ and $100 \%$ should be compared. At $2 \%$ hydrogen content the cell voltage shows a maximum variation of $0.3 \mathrm{~V}$. The lowest voltages at the exit are all around $0.45 \mathrm{~V}$. With the equilibrium voltage of the $\mathrm{Ni} / \mathrm{NiO}$ system at $800{ }^{\circ} \mathrm{C}$ of $0.738 \mathrm{~V}$ derived from the Free Gibbs enthalpy the corresponding oxygen partial pressures reaches $1.34 \times 10^{-14}$ bar [6]. Following the equilibrium conditions cell voltages below $0.700 \mathrm{~V}$ combined with relatively high oxygen pressures at the anode can lead to an oxidation of the anode and hence to harmful conditions for long-term operating systems [7]. In Fig. 5(f) the voltage distribution remains largely homogenous. Within each line of segments the voltage deviation is about $30 \mathrm{mV}$, decreasing from fuel inlet at segments 1, 5, 9, 13 to fuel outlet. At the outer segment line (segments 1, 2, 3, 4), especially at the edges, the effect of an insufficient glass sealing could be seen.
This is mainly attributed to the complex geometry of the set-up.

Impedance measurements are an appropriate method to assess the results obtained by the local current densities. The former approach of DLR, which only used one segmented bipolar plate [2], already allowed determination of local impedances. Variation of cell type and materials sometimes lead to inconsistent results of the area specific resistance with respect to the integral and the local spectra. The observed effects originated from the high electrical conductivity of the common metallic housing and a higher active area at the anode side involved in the electrochemical reaction at the operation of a single segment. For this reason, the new approach with double-sided segmentation was established and the resulting curves are displayed in Fig. 6. The overall and the local impedance are compared and show a fairly similar behaviour. The area specific polarisation resistance at open circuit voltage (OCV) (Fig. 6a) seems to have different slopes at hydrogen contents between $2 \%$ and $10 \%$ and between $10 \%$ and $50 \%$. 

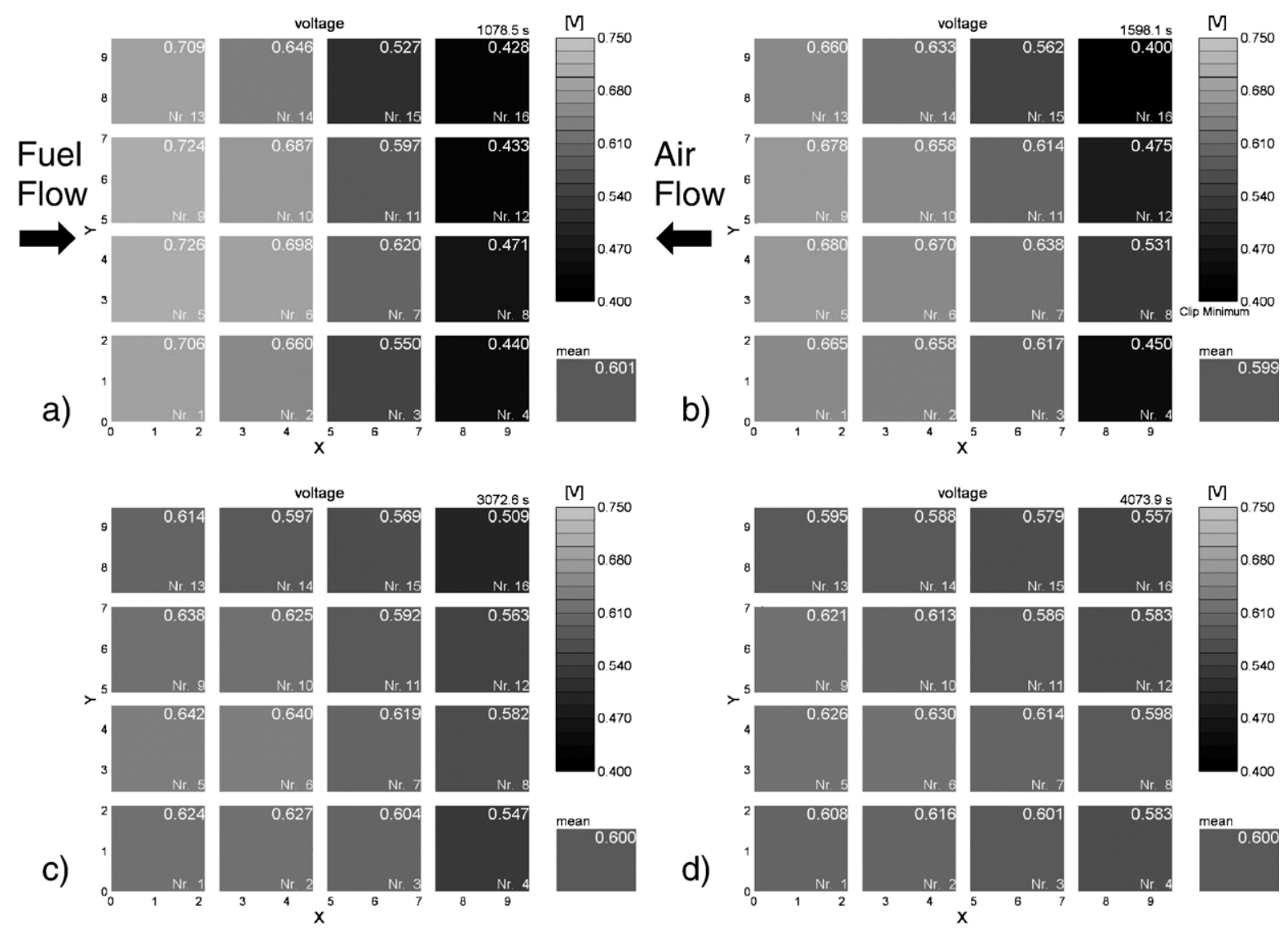

d)
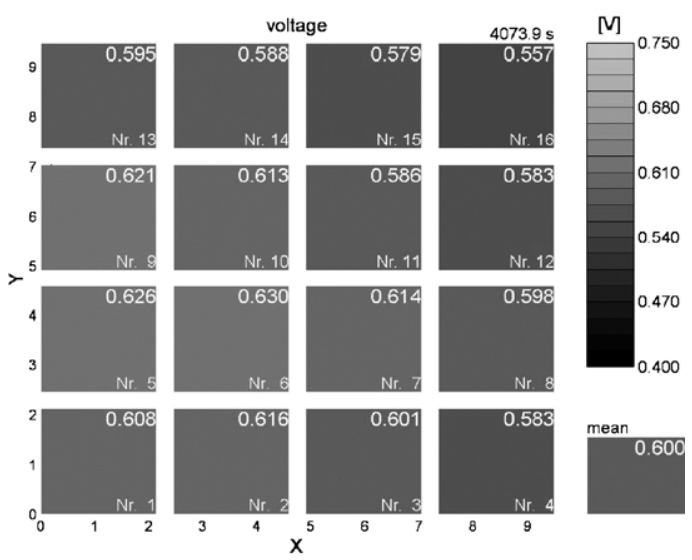

c)
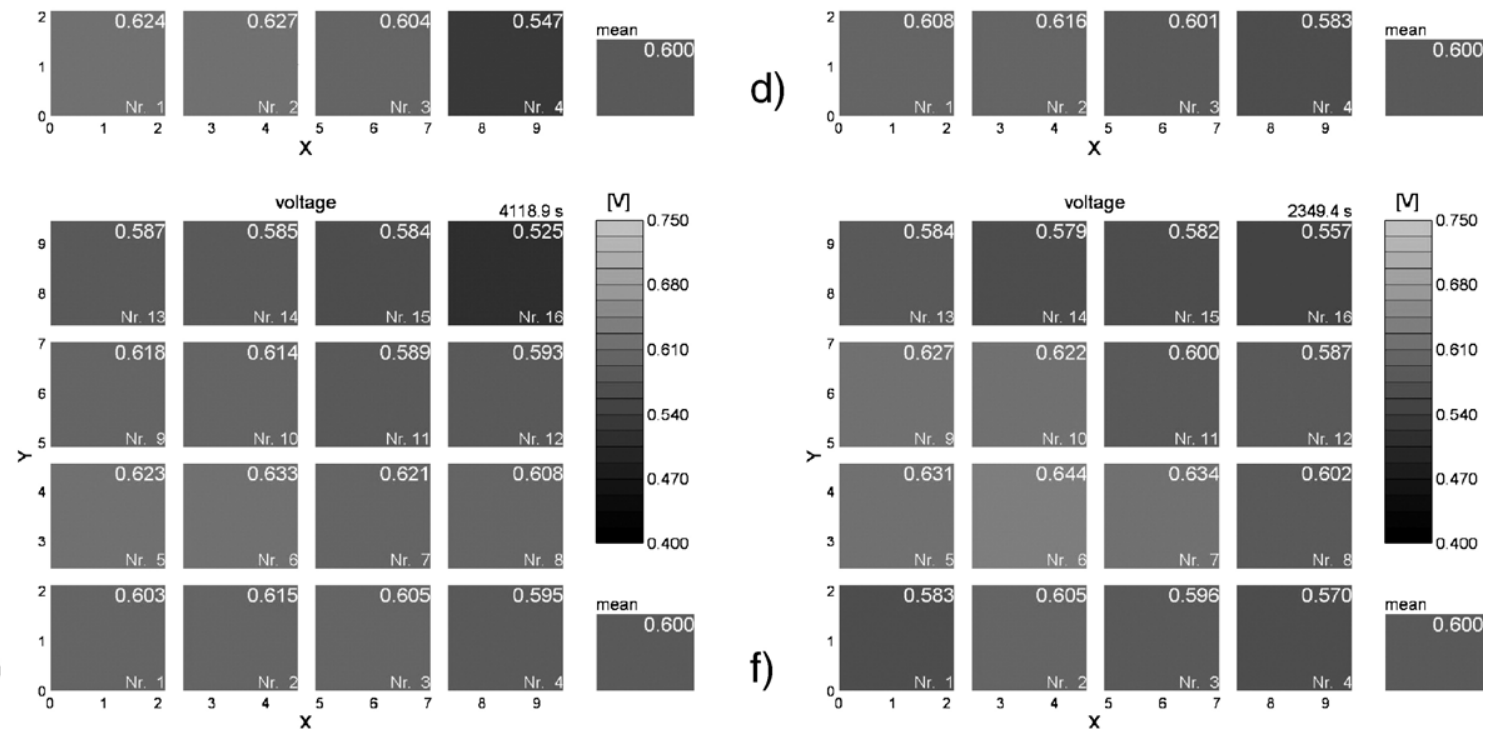

f)
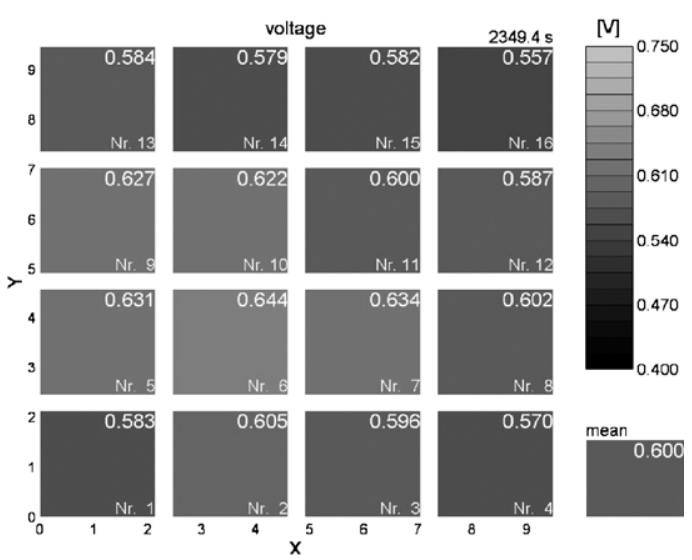

Fig. 5. Voltage distribution in the electrolyte supported cell ESC2 (INDEC) at different hydrogen concentrations, average cell voltage: $0.6 \mathrm{~V}$, operating temperature: $800{ }^{\circ} \mathrm{C}$, anode gas flow: $0.025 \mathrm{SlpM} / \mathrm{cm}^{2} \mathrm{H}_{2}+\mathrm{N}_{2}+3 \% \mathrm{H}_{2} \mathrm{O}$, cathode gas flow: $0.08 \mathrm{SlpM} / \mathrm{cm}^{2}$ air, $73.96 \mathrm{~cm}^{2}$; (a) $2 \% \mathrm{H}_{2}$, (b) $5 \% \mathrm{H}_{2}$, (c) $10 \% \mathrm{H}_{2}$, (d) $20 \% \mathrm{H}_{2}$, (e) $50 \%$ $\mathrm{H}_{2}$, (f) $100 \% \mathrm{H}_{2}$, counter flow.

This implies different dominating effects in the two regimes. In total the cell could be described by three processes: adsorption in the low frequency region (circa $2 \mathrm{~Hz}$ ), diffusion in the middle frequency region (circa $40 \mathrm{~Hz}$ ) and charge transfer in the high frequency region (circa $20 \mathrm{kHz}$ ) [8]. With hydrogen concentrations of $10 \%$ and above the processes show in total a negative double logarithmic correlation with the hydrogen content. With $2 \%$ and $5 \%$ hydrogen, the processes in the low and middle frequency regime begin to rise strongly, indicating a limitation in the adsorption and/or the diffusion processes. In Fig. 6(b) the cell is shown with an applied load of $200 \mathrm{~mA} / \mathrm{cm}^{2}$ for hydrogen contents of $10 \%, 20 \%, 50 \%$ and $100 \%$ and with an applied load of $50 \mathrm{~mA} / \mathrm{cm}^{2}$ for $2 \%$ and $5 \%$. Interestingly at $200 \mathrm{~mA} / \mathrm{cm}^{2}$ the polarization resistance is much lower and does not depend strongly on hydrogen content for all the segments and for the integral curve, for hydrogen contents above $10 \%$. This behaviour changes for lower hydrogen content. The dependence on hydrogen concentration in this region is significantly higher indicating an additional effect which is limiting the overall reaction.

From the above, the strong decrease of the current density could be related to the increase of the polarisation resistances at lower hydrogen contents. The higher absolute value of the slope for segment 8 under load should be considered under the 

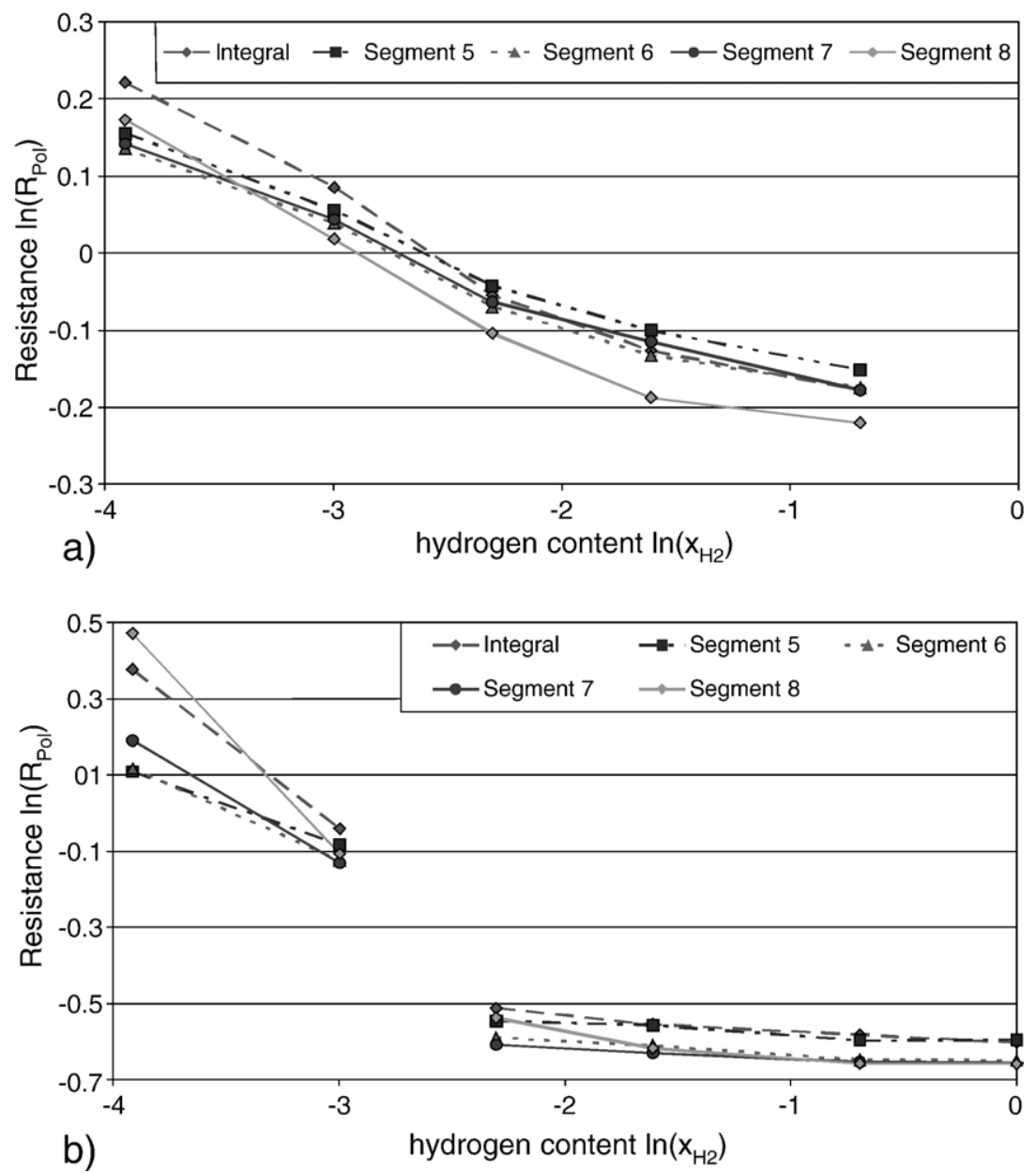

Fig. 6. Locally resolved and integral area specific resistance (ASR) as a function of hydrogen content in the fuel gas, operating temperature: $800{ }^{\circ} \mathrm{C}$, anode gas flow: $0.025 \mathrm{SlpM} / \mathrm{cm}^{2} \mathrm{H}_{2}+\mathrm{N}_{2}+3 \% \mathrm{H}_{2} \mathrm{O}$, cathode gas flow: $0.08 \mathrm{SlpM} / \mathrm{cm}^{2}$ air, $73.96 \mathrm{~cm}^{2}$, (a) OCV condition, (b) $200 \mathrm{~mA} / \mathrm{cm}^{2}$ at $100 \%, 50 \%, 20 \%, 10 \%$ hydrogen content, $50 \mathrm{~mA} / \mathrm{cm}^{2}$ at $5 \%, 2 \%$ hydrogen content.

constraint of the decrease in hydrogen concentration along the flow path. Therefore, segments 7 and 8 have in reality only concentrations of $1 \%$ hydrogen or less. The presented observa- tions become very important when cells are operated at high fuel utilisation and, as a consequence of the electrochemical reaction, different hydrogen levels are occurring across the whole cell area.

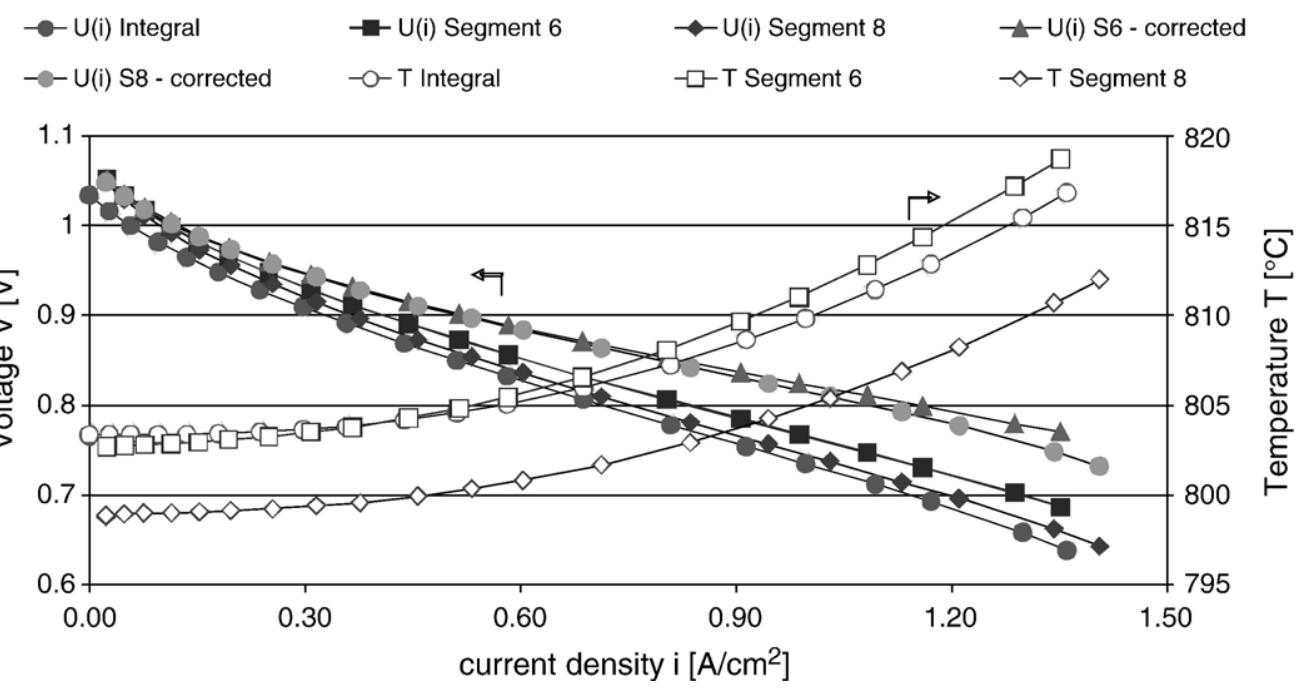

Fig. 7. Voltage, temperature and iR-corrected voltage (contact voltage drop) vs. current density of an anode supported cell ASC2 (INDEC), operating temperature: $800{ }^{\circ} \mathrm{C}$, anode gas flow: $3.60 \mathrm{~A} / \mathrm{cm}^{2}$ current density equivalent, $100 \% \mathrm{H}_{2}+3 \% \mathrm{H}_{2} \mathrm{O}$, air flow: $\lambda=2.7,73.78 \mathrm{~cm}^{2}$. 


\subsection{Contact resistances and temperature behaviour at high current densities}

High power densities in a stack may cause problems in operation, especially when the air flow is not sufficient to remove the heat from the system. The increase in temperature during operation is related to the losses, e. g. due to the entropy change of the reaction and to contact resistances. Therefore, Fig. 7 shows the measured $i-V$ curves and the $i-V$ curves corrected by the voltage drop originating from the contact resistances. The contact resistances could be determined from a voltage drop of $84 \mathrm{mV}$ at $1.4 \mathrm{~A}$ to be $0.06( \pm 0.006) \Omega \cdot \mathrm{cm}^{2}$. This is about $20 \%$ of the overall area specific resistance (ASR) under load and only about $10 \%$ of the value observed by Jiang [5]. For all segments almost identical contact resistances were found. The temperature in the middle of the cell (segment 6) reaches nearly $819{ }^{\circ} \mathrm{C}$ during operation, $16^{\circ} \mathrm{C}$ higher than without electrical load, and was still rising since the cell needed a long time to reach thermal equilibrium, even though the current remained constant. Interestingly also a significant variation of temperature was found in different segments indicating an inhomogeneous temperature distribution which is marked at high current densities. This short consideration indicates that cells with a high power output could experience thermal problems in stacks with reduced mass, especially in lightweight stacks which are developed for mobile applications.

\section{Conclusions}

The homogeneity of power density and of voltage along the flow path mainly depends on fuel utilisation. At low hydrogen contents, anode re-oxidation conditions may be established which could be dangerous for long-term operation of the cells. Impedance data under load showed two different regimes with respect to hydrogen content: At $10 \%$ and above the ASR is only slightly affected by the changes in hydrogen content. Below $10 \%$ hydrogen content, another dominating process occurs in the impedance spectra. The local and integral data of the impedance and of the current density showed good agreement. Heat production in a stack as a result of losses in the cell makes it necessary that the thermal management is considered for stack operation.

\section{Acknowledgement}

Supply of glass sealing by the IKTS Dresden and financial support of the BMW Group is gratefully acknowledged.

\section{References}

[1] V.V. Krishnan, et al., Solid State Ionics 166 (1-2) (2004) 191.

[2] P. Metzger, et al., in: M. Mogensen (Ed.), Sixth European SOFC Forum Proceedings, . European Fuel Cell Forum, Oberrohrdorf, Switzerland, vol. 2, 2004, p. 899.

[3] Ch. Wieser, et al., Journal of Applied Chemistry 30 (2000) 803.

[4] D.J.L. Brett, et al., Electrochemistry Communications, vol. 3, 2001, p. 628.

[5] S.P. Jiang, Journal of the Electrochemical Society, vol. 148 (8), 2001, p. A887.

[6] R. Bürgel, Handbuch Hochtemperatur-Werkstofftechnik - Grundlagen, Beanspruchungen, Hochtemperaturlegierungen, Vieweg Technik, 1998.

[7] S. Koch, P.V. Hendriksen, M. Mogensen, N. Dekker, B. Rietveld, B. de Haart, Tietz, in: M. Mogensen (Ed.), 6th European SOFC Forum, European SOFC Forum, Oberrohrdorf, 2004, p. 299.

[8] P. Metzger. "Ortsaufgelöste Charakterisierung von Festelektrolytbrennstoffzellen (SOFC) durch Messung betriebsrelevanter Größen entlang des Strömungsweges”. Doctoral Dissertation University of Stuttgart (2006). 